\title{
Design and optimization of a child-friendly dispersible tablet containing Isoniazid, Pyrazinamide and Rifampicin for treating Tuberculosis in pediatrics.
}

\author{
Suárez-González, Javier ${ }^{1,2,3, *}$; Santoveña-Estévez, Ana ${ }^{2,3}$; Soriano, Mabel ${ }^{2,3}$; Fariña, José $\mathbf{B}^{2,3}$ \\ ${ }^{1}$ Programa Doctorado en Ciencias de la Salud. Universidad de La Laguna, La Laguna, 38203. Spain \\ ${ }^{2}$ Facultad de Farmacia, Universidad de La Laguna, La Laguna, 38203. Spain \\ ${ }^{3}$ Instituto Universitario de Enfermedades Tropicales y Salud Pública de Canarias. Universidad de La Laguna, La \\ Laguna, 38203. Spain \\ * Corresponding author: Suárez González, Javier. \\ Mailing address: Dpto. Ingeniería Química y Tecnología Farmacéutica. \\ Facultad de Farmacia. Universidad de La Laguna. \\ Entrada Campus Anchieta, 4, 38206 San Cristóbal de La Laguna, Santa Cruz de Tenerife. Spain \\ Telephone number: +34922316502 ext.6965 \\ Email address: jsuarezg@ull.edu.es
}

This is an original manuscript / preprint of an article published by Taylor \&

Francis in Drug Development and Industrial Pharmacy on 26 Jan 2020, available online: http://www.tandfonline.com/10.1080/03639045.2020.1717516 


\section{Abstract:}

Objective: Develop a child-friendly Fixed Dose Combination (FDC) water-dispersible tablet for Tuberculosis (TB) treatment, with 50, 150 and $75 \mathrm{mg}$ of isoniazid (INH), pyrazinamide (PZA) and rifampicin (RFP) respectively. This new formulation must contain the lowest possible number of excipients, all accepted for pediatrics, and fulfill all the pharmacopoeia requirements for this type of tablet (friability, disintegration time, fineness of dispersion and content uniformity).

Significance: TB is an infectious disease which caused the death of 233,000 children in 2017. At present there is no adequate market dosage form available for children. There is, however, one in a prequalification phase by the World Health Organization but its composition contains some excipients which may not be suitable for pediatrics. Therefore, this new formulation would cover this therapeutic gap.

Methods: A factorial design, based on 3 quantitative factors (compression force and concentration of AcDiSol ${ }^{\circledR}$ and Explosol ${ }^{\circledR}$ ) at three levels each, was performed to elucidate their influence over disintegration time and friability. In addition, the influence of the press speed on disintegration time, friability, tensile strength, fineness of dispersion and content uniformity over the target tablet was tested. A stability test was done following ICH guideline for accelerated conditions.

Results: A water-dispersible tablet was developed according to international recommendations in terms of excipients for pediatrics and meeting $\mathrm{Ph}$. Eur. requirements. In addition, its production has been optimized to be elaborated at maximum eccentric press speed but maintaining quality requirements.

Conclusion: A high-quality child-friendly FDC water-dispersible tablet was developed improving the treatment of TB in pediatric.

Keywords: Tuberculosis; children; pediatric; dispersible tablet; treatment; direct compression.

\section{Introduction}

Tuberculosis (TB) caused the death of 233,000 children in 2017 and one of the main reasons of mortality was the lack of child-friendly formulations for its treatment [1]. Since 2015 The World Health Organization (WHO), the National Institutes of Health (NIH) 
and The European Medicines Agency (EMA) have been publishing articles regarding the need for efficient studies for global health and formulations focused on pediatrics for treating TB: list of pediatrics needs [2-6].

TB is an infectious disease produced by Mycobacterium tuberculosis. The first-line treatment is based on the combination of three active pharmaceutical ingredients (APIs): isoniazid (INH), pyrazinamide (PZA) and rifampicin (RFP). In 2014, WHO increased its daily doses to $10 \mathrm{mg} / \mathrm{kg}$ of INH, $35 \mathrm{mg} / \mathrm{kg}$ of PZA and $15 \mathrm{mg} / \mathrm{kg}$ of RFP based on: previous experience, the increase of resistance and dose inefficiency. Thus, according to the WHO, the dose of API per tablet should be 50, 150 and $75 \mathrm{mg}$ of INH, PZA and RFP respectively [7]. However, according to Piñeiro et al. these doses may not be not suitable for all ages and may produce cases of under or overdoses [8].

As there is scientific evidence proving the benefits to the patient's health when a fixeddose combination (FDC) dosage form is used, this becomes the main aim to improve TB treatment in pediatrics [9-11]. The best option seems to be the development of orodispersible tablets, which disintegrates inside the mouth. However, this is not possible due to the high doses of the different APIs required to treat TB. The development of an orodispersible tablet with such doses means a larger tablet and the increase of the possibilities of choking and chewing. Therefore, an interesting alternative could be the development of water-dispersible tablets. In 2018 TB alliance presented a FDC dispersible tablet which has been prequalified by the WHO. This new formulation is made with the recent recommended doses of APIs, but contains excipients such as: povidones, aspartame and flavors which may not be suitable for pediatrics, as EMA and other institutions recommend [12-14].

The aim of this study is to develop a child-friendly FDC dispersible tablet for TB treatment with 50, 150 and $75 \mathrm{mg}$ of INH, PZA and RFP respectively using direct compression. This new tablet must be made with the lowest number of excipients and in the lowest percentages. All of them must be accepted for pediatrics following EMA guidelines regarding drug formulation. In addition, such tablets have to be suitable for different ages and body weights [4]. Furthermore, it must comply with $\mathrm{Ph}$. Eur. quality attributes for dispersible tablets (disintegration time, friability, content uniformity, fineness of dispersion and effectiveness of the score lines in the case of 15-mm tablets) [15].

\section{Materials and Methods.}

\subsection{Materials}


INH $\left(\right.$ Acofarma $\left.^{\circledR}\right)$, PZA (Sygma-Aldrich $\left.{ }^{\circledR}\right)$ and RFP $\left(\right.$ Fagron $\left.^{\circledR}\right)$ has been used as the API to develop a FDC Tablet for TB treatment. The following excipients were used: AcDiSol ${ }^{\circledR}$ (Croscarmellose Sodium, FMC Corp.), Avicel ${ }^{\circledR}$ PH102, (Microcrystalline Cellulose, FMC Corp.), Explosol ${ }^{\circledR}$ (Sodium Starch Glycolate, Blanver), CompactCel ${ }^{\circledR}$ (Isomalt, sucralose, betadex, carboxymethylcellulose sodium, Biogrund $\mathrm{GmbH}$ ), Luzenac ${ }^{\circledR}$ (talc, Imerys Talc) and CabOSil ${ }^{\circledR}$ (fumed silica, Cabot CorporaFon). Purified water was obtained from a water purification system (Puranity TU 12, VWR, USA).

\subsection{UHPLC analysis.}

All APIs were analysed by reversed phase Ultra High-Performance Liquid Chromatography (UHPLC) in an Acquity UHPLC® H-Class System (Waters Corporation, Milford, MA) using Astra 6.0.1 as acquisition software (Chromatographic Manager, Waters Corporation).

INH and PZA were analysed with a method based on an UHPLC gradient method [16] and RFP was analysed using a method adapted from High Performance Liquid Chromatography (HPLC) [17]. For both methods, the chromatographic conditions were: XSelect $^{\mathrm{TM}} \mathrm{CSH}^{\mathrm{TM}} \mathrm{C} 18(75 \mathrm{~mm} \times 2.1 \mathrm{~mm}$ id, $2.5 \mu \mathrm{m})$ reserved phased column; Acetonitrile:Phosphate Buffer $\mathrm{pH} 3.7$ as mobile phase in proportion of 2:98 (v/v) for INH and PZA, and 38:62 (v/v) for RFP; flow rate of $0.5 \mathrm{ml} / \mathrm{min} ; 242 \mathrm{~nm}$ of wavelength. All chemicals and reagents were analytical grade. All samples and solvents were filtered with $0.2 \mu \mathrm{m}$ pore-size filters (Millipore, Billerica, MA) before proceeding with chromatographic analysis.

The validation of the analytical method was done according to the ICH guideline using standard solutions with concentrations from 10.0 to $27.0 \mu \mathrm{g} / \mathrm{ml}$ for INH, PZA and RFP. [18]. The variance analysis (ANOVA) was carried out to confirm the linearity of the method.

The method precision (as repeatability) was determined by a sixfold analysis of the same sample. System accuracy was expressed as percentage recovery by assay of a known added amount of drugs $(n=9)$. The detection and quantitation limits, based on the standard deviation of the response and slope, were also checked for each API. Robustness was also tested to establish the effect of operational parameters on the analysis results. To calibrate the UHPLC system and monitor its performance, a solution sample containing all APIs was analyzed daily as standard. 
A solution of INH, PZA and RFP with a $\mathrm{pH}$ of 7 was stored at $50^{\circ} \mathrm{C}$ (Heaeus UT 6060 , Spain) during $72 \mathrm{~h}$ in order to observe the capability of the method concerning degradation and to detect/quantify degradation products.

In addition, the method must be capable of analyzing the content and obtain the declared amount of APIs in each tablet from a complex matrix (non-soluble excipients mainly). For this reason, each ingredient of one tablet was weighed, dissolved in $50 \mathrm{ml}$ of methanol and diluted with water up to $250 \mathrm{ml}$. Then, it was filtered using $110 \mathrm{~mm}$ filter paper (Albet LabScience, Spain) and diluted to UHPLC analysis. This procedure was repeated 10 times and the average amount was calculated and expressed as labeled content.

\subsection{Optimization of blending process.}

APIs and excipients were weighted and blended in a V-Type Blender (FTLMV-0,5, FILTRA ${ }^{\circledR}$ VIBRACIÓN, Spain) with a mixing power of $0.12 \mathrm{~kW}$ for 5,10 and 15 minutes. At each time the powder mix was placed in a rectangular container which was divided in 5 different zones and a sample of $200 \mathrm{mg}$ was taken. Finally, its content in API was determined as described above.

Process Capability index ( $\mathrm{CpK}$ in equation 1) was used to know if the mixing process satisfied quality specification in terms of content uniformity.

$$
C p K=\min \left(\frac{U S L-\mu}{3 \sigma}, \frac{\mu-L S L}{3 \sigma}\right)
$$

where $\mu$ and $\sigma$ are average and standard deviation respectively and USL/LSL are upper and lower specification limits using $\pm 15 \%$ as limits for the theoretical content that should be in these samples.

Flow properties of the powder mix were evaluated according to $\mathrm{Ph}$. Eur. tests: angle of repose (Granulate Tester GTB, Erweka, Germany), Carr's Index and Hausner's Ratio (Tapped Density Tester SVM 223, Erweka, Germany). Other flow properties such as: flow rate, volume flow rate, mass flow rate and flow angle were tested using a $100 \mathrm{ml}$ steel hopper and a $15 \mathrm{~mm}$ cylindrical nozzle $[19,20]$.

\subsection{Preparation of the tablets.}

Tablets were obtained by direct compression of the powder mix in an instrumented eccentric tablet machine XP1, Research Tablet Press (Korsch, Germany) using 15$\mathrm{mm}$ flat-faced bisect punches (FFBP) and 12-mm flat-faced with beveled edge (FFBE). Tablets were produced with different compressions forces and press speed. Compression force and press speed were controlled by PharmaReseach ${ }^{\circledR}$ (Korsch, Germany).

\subsection{Experimental design.}


The variables selected for the experimental design of dispersible tablets were the levels of excipients with function as disintegrate (AcDiSol ${ }^{\circledR}$ and Explosol $\left.{ }^{\circledR}\right)$ and compression forces $(\mathrm{kN})$. These were chosen in order to evaluate their influence on disintegration time and friability on 15-mm tablets. For this purpose, a factorial design based on 3 quantitative factors (compression force and concentration of AcDiSol ${ }^{\circledR}$ and Explosol ${ }^{\circledR}$ ) at three different levels each was used. Table 1 shows the coded levels and values of the design variables. Therefore, a $3^{3}$-factorial design was performed with 27 different combinations of variables and replicating the center point three times, which meant the elaboration of 30 batches. Sodium starch glycolate shows better properties than croscarmellose sodium according to the literature [21-25]. For this reason, percentages from $2-9 \% \mathrm{w} / \mathrm{w}$ of Explosol $\AA$ where used and $0-5 \% \mathrm{w} / \mathrm{w}$ of AcDiSol $\AA$ in order to verify if the second one improves disintegration time or friability.

Table 2 shows the final composition of formulation 1 to 9, each of which was compressed at three compression forces to develop the dispersible tablets.

A statistical approach is used to fit a model using Design-Expert 9.0.3 (Stat-Ease Inc., Minneapolis, MN, USA). Logarithmic values for disintegration time and inverse of square root for friability were used to improve the quality of the model. P-value was used in each case to know which terms were significant for each response and R-squared $\left(\mathrm{R}^{2}\right)$, adjusted R-squared $\left(\mathrm{R}^{2}\right.$ adj $)$ and predicted $\mathrm{R}$-squared $\left(\mathrm{Q}^{2}\right)$ were used to measure the goodness of the model [26]. All tests were performed at 5\% level of significance $(\alpha=$ 0.05). The complete model equation is as follows:

$$
y=\beta_{0}+\beta_{A} X_{A}+\beta_{B} X_{B}+\beta_{C} X_{C}+\beta_{A B} X_{A} X_{B}+\beta_{A C} X_{A} X_{C}+\beta_{B C} X_{B} X_{C}+\varepsilon
$$

where $\mathrm{A}$ is $\operatorname{AcDiSol}{ }^{\circledR}(\%, w / w), B$ is $\operatorname{Explosol}{ }^{\circledR}(\%, w / w)$ and $C$ is compression force $(\mathrm{kN})$.

\subsection{Optimization and characterization of the dispersible tablet.}

When a formulation complied with the requirements of dispersible tablets in terms of friability and disintegration time the influence of press speed is tested tableting at 10, 25 and 50 cycles/minute. Tablets are then characterized testing disintegration time, friability, tensile strength, content uniformity, fineness of dispersion and effectiveness of score lines as critical quality attributes (CQAs)

Disintegration time: Disintegration time of 6 tablets was determined using a disintegration tester (Disintegrator Tester ZTx20, Erweka, Germany) following the $\mathrm{Ph}$. Eur. recommendations [27]. The time that all the tablets disintegrated was used or accepted for the study. 
Friability: This was carried out using a friability test (Tablet Friability/Abrasion Tester TAR Series, Erweka, Germany) following the Ph. Eur. guideline [28].

Tensile strength: This was measured for each batch (Hardness Tester TBH 125 Series, Erweka, Germany) following the recommendations given by $\mathrm{Ph}$. Eur. and USP, equation $3[29,30]$.

$$
T S=\frac{2 \cdot p}{\pi \cdot d \cdot l}
$$

where $\mathrm{p}, \mathrm{d}$ and 1 are: tablet breaking force, tablet diameter and tablet thickness respectively.

Content Uniformity: This was tested according to the uniformity of dosage units test by $\mathrm{Ph}$. Eur. [31]. The content of 10 dispersible tablets for each batch were analyzed using a UHPLC system and their acceptance value was calculated.

Fineness of dispersion: Two dispersible tablets dissolved in $100 \mathrm{ml}$ of purified water must pass through a sieve with $710 \mu \mathrm{m}$ of nominal mesh aperture [15].

Effectiveness of score lines: As 15-mm tablets have score lines, suitability must be tested in terms of mass uniformity. First, 30 tablets were chosen randomly and broken by hand. One half was used for the test and the other half were rejected. 30 parts were weighed, and the average mass was calculated.

\subsection{Tableting properties}

Critical Process parameters, such as compression force and press speed, were controlled and signals were imported from Extended Data Analysis ${ }^{\circledR}$ (EDA) (Korsch, Germany) and analyzed using a macro for MS Excel (Microsoft Corporation). Compression process were controlled using a control chart of compression forces and establishing stop reasons when the compression force was greater than $3 \%$ of target force.

$\mathrm{K}$ value was obtained from the slope of straight-line interval of the Heckel plot using the data from the space between the upper and lower punch and matrix diameter to calculate the relative density of the material (D) according to equation $4[32,33]$.

$$
\ln \left(\frac{1}{1-D}\right)=K \cdot F+A
$$

where $\mathrm{F}$ is compression force and $\mathrm{A}$ is a constant.

Mean yield pressure (Py) and strain-rate sensitivity (SRS) were calculated using K following equations 5 and 6.

$$
\begin{gathered}
P y=\frac{1}{K} \\
S R S=\frac{P y 1-P y 2}{P y 1} \cdot 100
\end{gathered}
$$


where Py1 and Py2 are the yield pressure at low (10 strokes/min) and high speed (50 strokes/min), respectively.

Plasticity, equation 7, were estimated from the force-displacement compression profile using the average energy consumption within the different compaction phases: W1 (friction work), W2 (net work) and W3 (elastic work). [32,34-36].

$$
P L=\left(\frac{W 2}{W 2+W 3}\right) \cdot 100
$$

\subsection{Stability test.}

A stability test was done placing $15-\mathrm{mm}$ tablets under accelerated conditions $\left(40 \pm 2{ }^{\circ} \mathrm{C} / 75 \% \pm 5\right.$ Relative Humidity $\left.(\mathrm{RH})\right)$ following ICH guideline: stability testing of new drugs substance and products (Q1A(R2)). The content of INH, PZA and RFP was measured during 6 months of storage and express as \% of declared value [37].

\section{Results and Discussion.}

The ANOVA of the linear regression confirmed the linearity of the analytical method to all the API studied through rejection of the null hypothesis of deviation from linearity for a significance level of 0.05 . Characteristics of the method for each API are shown in table 3.

The average extraction yield of each API from the tablets are: $103 \pm 2.07 \%$ for INH, 98.4 $\pm 1.95 \%$ for PZA and $98.33 \pm 0.95 \%$ for RFP. In this case the average extraction is correct as it is near to $100 \%$.

Figure 1 shows the chromatogram for each API obtained by the UHPLC method as pure patterns and also how these peaks change over time under $50^{\circ} \mathrm{C}$ of storage.

The selection of excipients was carried out taking into account the complexity of our ideal formulation. All excipients need to be suitable for direct compression and provide good flow properties to ensure API's content. A taste-masking excipient is needed as INH has a bitter taste and they have to be accepted for pediatrics. In addition, the tablets must disintegrate in less than 3 minutes and have a friability below $1 \%[28,38]$.

The first selection of excipients was done taking into account the most common excipients used in published papers related to the development of dispersible tablets: croscarmellose sodium, sodium starch glycolate, crospovidone, microcrystalline cellulose, magnesium stearate and talc [39-43]. Therefore, we selected the excipients according to their function (lubricant, (super)disintegrant, glidant, etc.), physical characteristics (water-solubility, particle size and shape) and safety. 
All of these excipients are generally recognized as safe (GRAS). However, due to the number of tablets which have to be taken in order to treat $\mathrm{TB}$, some excipients were preferred instead of others. Crospovidone was not included in the formulation due to the lack of data in terms of acceptable daily intake and safety in children. In addition, as a lubricant, talc was preferred instead of magnesium stearate because of its laxative effect and mucosal irritation when large quantities are taken [23].

Previous test of powder flow, mixing time to obtain a homogenous powder and tableting process were done to find the right number and percentage of each excipient.

Our objective was to obtain dispersible tablets with a disintegration time below 3 minutes, according to WHO requirements. Hence, a high disintegration force with a low amount of excipient is required and therefore, superdisintegrants were preferred.

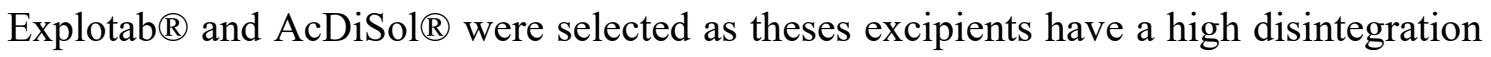
force at low concentrations and physical properties useful to develop these tablets. The disintegration force of Explotab ${ }^{\circledR}$ does not seem to be affected by concentration of lubricant or compression force. AcDiSol ${ }^{\circledR}$ also has a good disintegration force and imparts exceptional long-term dissolution stability in comparison to other superdisintegrants. However, at high concentrations of excipient, tablets could become soft when stored with an elevated relative humidity [21-25].

The relationship between concentrations of excipient and disintegration time and friability are very important and therefore studied carefully.

During the first trails, adherence of powder mix to the surface of punches was noticed which made the tableting process difficult. To reduce such adherence, talc (Luzenac ${ }^{\circledR}$ ) was increased from 1 to $2.5 \% \mathrm{w} / \mathrm{w}$ improving the situation.

CompactCel ${ }^{\circledR}$ was added to the formulation in order to mask the bitter taste of INH; one of the problems of poor adherence to treatment [44]. This complex excipient was chosen instead of other excipients due to the composition (isomalt, sucralose, betadex, carboxymethylcellulose sodium), and also because of the superior performance in terms of disintegration time and friability. It was added at $7 \% \mathrm{w} / \mathrm{w}$ because, along with microcrystalline cellulose (Avicel $\left.{ }^{\circledR}\right)$, reduced powder adherence to punch surfaces [45]. The flow properties according to Carr's Index, Hausner's Ratio and flow angle were very poor when no glidant was used. Although the incorporation of $1 \% \mathrm{w} / \mathrm{w}$ CabOSil $\AA$ did not improve the value of these parameters it produced a relevant improvement in flow rate, from 95.8 to $28.8 \mathrm{~s} / 100 \mathrm{~g}[19,20,23]$. 
When $50 \% \mathrm{w} / \mathrm{w}$ of Avicel ${ }^{\circledR}$ was added, no punch surfaces adherence was observed, regardless of type (FFBP or FFBE), and disintegration time and friability were near to the recommendations established by EMA and WHO for dispersible tablets: 2.33 min and $0.87 \%$. Moreover, the use of this concentration of Avicel ${ }^{\circledR}$ reduced the blending process from 20 to 15 minutes.

Therefore, taking into account the results of the previous test, we adjusted the excipients and their concentrations as follows: $2.5 \% \mathrm{w} / \mathrm{w}$ Luzenac $\AA, 1 \% \mathrm{w} / \mathrm{w}$ CabOSil $\AA$, $7 \% \mathrm{w} / \mathrm{w}$ CompactCel ${ }^{\circledR}$ and $50 \% \mathrm{w} / \mathrm{w}$ of Avicel ${ }^{\circledR}$.

Cpk value could be used to classify production process, according to USP: "exceeding 1.33 show that the process is adequate to meet specifications [46].

To establish an optimum mixing time, Cpks values were estimated. Table 4 shows the evolution over time for each API. As can be seen, at 15 minutes the blending process is under control $(\mathrm{CpK}>1.33)$. INH is the only one that required more time to reach this $\mathrm{CpK}$ value, due to the lower proportion in the mixture. The other APIs showed $\mathrm{CpK}>$ 1.33 after 5 minutes of mixture.

According to Hausner's ratio and Carr's index, the flow properties of the powder can be classified as acceptable, which agrees with angle of repose (39.3, fair). Mass flow rate, volume flow rate, flow rate and flow angle were: $4.59 \pm 0.99 \mathrm{~g} / \mathrm{s}, 10.1 \pm 0.40 \mathrm{~s} / 100 \mathrm{ml}$, $20.0 \pm 0.87 \mathrm{~s} / 100 \mathrm{~g}$ and $78.2 \pm 1.72^{\circ}$ respectively.

As already stated, our aim was to evaluate the influence of the concentration of excipients (AcDiSol ${ }^{\circledR}$ and Explosol ${ }^{\circledR}$ ) and compression force on the disintegration time and friability of $15-\mathrm{mm}$ water-dispersible tablets.

The results obtained with the different batches of tablets produced according to the experimental design are shown in table 5.

Using a regression analysis, the relation between the studied factors (excipients and compression force) with the changes produced in tablet properties (disintegration time and friability) were studied. The statistical parameters to evaluate the goodness of the model is shown in table 6.

Values for $\mathrm{R}^{2}, \mathrm{R}^{2}$ adj and $\mathrm{Q}^{2}$ are greater than 0.5 , and their difference is not less than 0.3 . Therefore, the indicators suggest a high quality of the model for fitting and predicting the effects on disintegration time and friability [26]. This lack of Fitting in both responses were not significant.

Once the non-statistically significant terms were removed, the model equation for each response was: 
$\log ($ disintegration time $)=2.11-0.04 \cdot \mathrm{B}+0.11 \cdot \mathrm{C}-0.09 \cdot \mathrm{AC}$

$\frac{1}{\sqrt{\text { Friability }}}=0.99-0.06 \cdot B+0.13 \cdot \mathrm{C}-0.05 \cdot A B$

where: $A$ is $\operatorname{AcDiSol}{ }^{\circledR}(\%, w / w), B$ is $\operatorname{Explosol} \AA(\%, w / w)$ and $C$ is compression force $(\mathrm{kN})$.

As may be seen from the equations, the concentration of A does not have any statistically significant influence over disintegration time (P-value: 0.38 ) or friability (P-value: 0.37 ). The concentration of $\mathrm{B}$ has a negative influence over disintegration and a positive one over friability, mainly because of its properties as a superdisintegrant (P-value: 0.0109 and $<0.0001$, respectively) [23]. C, as expected, increase disintegration time and reduce friability of the tablet (P-value $<0.0001$ for both responses).

There are two interactions which are statistically significant $(\mathrm{P}$-value $<0.0001)$ and both showed a negative effect over their response: $\mathrm{AC}$ in the case of disintegration time and AB for friability. Such negative effect means that the effect of one parameter is lower when the value of the other is high.

Figure 2 shows the 3D response surface for the predicting model. In red, highest desirability, the conditions where the minimum disintegration time and friability is obtained using the lowest number of excipients. Therefore, the tablets that meet these conditions are those corresponding to formulation 3 (table 2) produced without AcDiSol ${ }^{\circledR}$ with $9 \% \mathrm{w} / \mathrm{w}$ of Explosol ${ }^{\circledR}$ and a compression force of $16 \mathrm{kN}$ (batch number 9 in table 5).

This batch was also compressed using the 12-mm FFBE punches with the same compression pressure $(9 \mathrm{kN} / \mathrm{cm} 2)$. As can be seen, in table 7, when the $12-\mathrm{mm}$ punches were used, the weight of the tablets was reduced by $50 \%$ and they meet disintegration time ( $<3 \mathrm{~min})$ and friability test $(<1 \%$ less of initial weight)

Since the previous tableting process was done at 10 cycles/min press speed, the influence of this on CQAs using 15- and 12-mm punches at a compression force of 16 and $10 \mathrm{kN}$ respectively was tested.

Table 8 shows how quality attributes changes with press speed for both punches. Due to the improved strength transmission at slower press speed, at $10 \mathrm{cycles} / \mathrm{min}$ tensile strength showed the highest value whereas at 50 cycles/min showed the lowest: this will have an influence on friability and disintegration time. At the slowest press speed, as the tensile strength increases friability decreases and so will require a longer period to disintegrate. $12-\mathrm{mm}$ tablets showed a 6 times lower friability than the larger ones. This 
could be explained by the best strength transmission when a flat face is used compared to when score lines are present. Furthermore, due to the beveled edge in these tablets the possibility of chipping during the friability test is reduced [47,48]. Acceptance value (VA) was always below 15, regardless of press speed or the type of punches used.

In the case of $15-\mathrm{mm}$ tablets, the tableting process could be done up to 25 cycles/minute ensuring good quality attributes since at 50 cycles/minute friability is greater than $1 \%$. The highest press speed could be used for the 12-mm tablets since it showed good quality attributes at this speed. In this sense, this could be an alternative, in terms of industrial development, due to the improved friability in comparison with 15-mm tablets. However, as these tablets have $50 \%$ of the required daily dose, two tablets would need to be taken instead of one.

Finally, effectiveness of score lines: $15-\mathrm{mm}$ tablets produced at 25 cycles/minute fulfilled this test since none of the 30 half tablets deviate in more than $\pm 15 \%$ of the average mass, which means that they could be split correctly. Moreover, the subdivision of these tablets could be useful to improve the dose scheme.

Compaction data obtained from an instrumented tableting machine enables rationale scientific designing of a tablet formulation with the desired quality attributes. Additionally, the parameters derived from Heckel plot like mean yield pressure and SRS or those obtained from compression curves, like plasticity, give us information which is important for production efficiency and the final tablet quality $[33,49,50]$.

The material had a plasticity of $92.0 \pm 0.20(n=26)$ and it is independent of matrix diameter and press speed. Mean yield pressure is not influenced by press speed but depends on the diameter of the matrix: $12-\mathrm{mm}(3.59 \pm 0.68 \mathrm{kN})$ and $15-\mathrm{mm}(81.0 \pm 1.75$ $\mathrm{kN}), \mathrm{n}=5$.

The SRS value could be useful in order to catalogue our product according to Robert and Rowe classification which goes from very soft to a moderately hard/brittle material [36]. Taking into account the low values obtained for SRS, 3.5 and 21.8 for $15-\mathrm{mm}$ and 12$\mathrm{mm}$ respectively, the material seems not to be affected by press speed.

In the literature it is well describe the instability of RFP when it is in combination with INH in solution. However, there is not data about the stability of these APIs at pediatric doses in solid state. Singh and Mohan in 2003 described a reduction upto 7\% of RFP content on a four-drug FDC available in the market for adults [51]. Moreover, this solid dosage form included Ethambutol in its composition which is able to caption moisture making FDC more instable [52]. 
Figure 3 shows the variation of drug content of 15- $\mathrm{mm}$ tablets storage at accelerated conditions for 6 months express as $\%$ of declared value. In our formulation all APIs remained inside the limit of $\pm 5 \%$ of drug content till 6 months of storage. More stability studied are currently ongoing in the laboratory to study the influence of light or moisture.

\section{Conclusions}

According to the results obtained, a high-quality child-friendly water-dispersible tablet containing INH, PZA and RFP for TB treatment has been developed in a design space using the lowest number of excipients and in the lowest proportion; all of them accepted by pediatrics (as EMA recommends). This new dosage form meets compendial requirements in terms of friability, disintegration time and content uniformity and could be a vial alternative for treating tuberculosis in pediatrics.

\section{Acknowledgments}

This work was supported by a research project (ProID2017010094) funded by Gobierno de Canarias, Spain. The authors would like also to thank CajaSiete and Universidad de La Laguna for their contribution with a predoctoral contract and Biogrund GmbH, IMCD Iberia, Acofarma and DFE Pharma for the selfless donation of raw materials.

Disclosures: No authors have any financial/conflicting interests to disclose. 


\section{References}

[1] World Health Organization. Global Tuberculosis Report: 2018. 2018; Available at: https://www.who.int/tb/publications/global_report/en/. Accessed 01/18, 2019.

[2] National Institute of Health and Human Development (NIH). Best Pharmaceuticals for Children Act (BPCA) Priority List of Needs in Pediatric Therapeutics 2015. 2015: https://bpca.nichd.nih.gov/prioritization/status/Documents/2015_Priority_List.pdf.

Accessed 05/18, 2019.

[3] National Institute of Health and Human Development (NIH). Best Pharmaceuticals for Children Act (BPCA) Priority List of Needs in Pediatric Therapeutics 2018. 2018: https://bpca.nichd.nih.gov/prioritization/status/Documents/PriorityList2018.pdf.

Accessed 05/18, 2019.

[4] The European Medicines Agency (EMA). Guideline on pharmaceutical development of medicines for paediatric use. EMA/CHMP/QWP/805880/2012 Rev. 2. 2014; Available

http://www.ema.europa.eu/docs/en_GB/document library/Scientific_guideline/2013/07 /WC500147002.pdf. Accessed 05/14, 2019.

[5] World Health Organization. Guidance for National Tuberculosis Programmes on the Management of Tuberculosis in Children. 2nd Edition ed. Geneva: World Health Organization.; 2014.

[6] World Health Organization. Model Lists of Essential Medicines for Children. 2017; Available at: http://apps.who.int/iris/bitstream/handle/10665/273825/EMLc-6eng.pdf?ua=1. Accessed 06/15, 2019.

[7] World Health Organization, TB alliance, Unicef. New fixed-dose combinations for the treatment of TB in children. 2016; Available at: http://www.who.int/tb/FDC_Factsheet.pdf. Accessed 03/14, 2019.

[8] Piñeiro Pérez R, Santiago García B, Rodríguez Marrodán B, Baquero-Artigao F, Fernández-Llamazares $\mathrm{CC}$, López-Ramos $\mathrm{MG}$, et al. Recomendaciones para la elaboración y administración de fármacos antituberculosos en niños. Segunda fase del Proyecto Magistral de la Red Española de Estudio de la Tuberculosis Pediátrica (pTBred). An Pediatr (Barc) 2016;85(6).

[9] Agertt VA, Bonez PC, Mizdal CR, Rossi GG, Flores VdC, Anraku de Campos MM. In vitro antimicrobial efficacy of a fixed-dose combination of RHZE against $M-$ tuberculosis. Braz. J. Pharm. 2016;52(3):575-580.

[10] Lima GC, Silva EV, Magalhaes PdO, Naves JS. Efficacy and safety of a four-drug fixed-dose combination regimen versus separate drugs for treatment of pulmonary tuberculosis: a systematic review and meta-analysis. Brazilian J Microbiol 2017;48(2):198-207.

[11] Svensson EM, Yngman G, Denti P, McIlleron H, Kjellsson MC, Karlsson MO. Evidence-Based Design of Fixed-Dose Combinations: Principles and Application to Pediatric Anti-Tuberculosis Therapy. Clin Pharmacokinet 2017 Aug 04 (Epub 2017 Aug $04)$.

[12] The Global Fund. List Of Tuberculosis Pharmaceutical Products classified according to the Global Fund Quality Assurance Policy. 2018; Available at: https://www.theglobalfund.org/media/4757/psm_productstb_list_en.pdf?u=6366793069 30000000. Accessed 01/14, 2019.

[13] World Health Organization. Rifampicin/Isoniazid/Pyrazinamide 75mg/50mg/150mg Dispersible Tablets (Macleods Pharmaceuticals Limited), TB309. 2018; Available at: https://extranet.who.int/prequal/sites/default/files/TB309part4v1.pdf. Accessed 01/14, 2019. 
[14] TB alliance. WHO Prequalifies Childhood TB Medicine. 2017; Available at: https://www.tballiance.org/news/who-prequalifies-childhood-tb-medicine. Accessed 02/12, 2019.

[15] Ph. Eur. EP. Tablets. In: Council of Europe, editor. 8th ed. Strasbourg, France; 2014.

[16] Nguyen DT-, Guillarme D, Rudaz S, Veuthey J. Validation of an ultra-fast UPLCUV method for the separation of antituberculosis tablets. J Sep Sci. 2008;31(6-7):10501056.

[17] Moreno-Exebio L, Grande-Ortiz M. Validation of a liquid chromatography method for rifampicin determination in human plasma. Rev Peru Med Exp Salud Publica. 2014;31(1):56-61.

[18] ICH, The International Conference on Harmonisation. Validation Of Analytical Procedures: Text And Methodology Q2(R1). Available at: http://www.ich.org/fileadmin/Public Web Site/ICH_Products/Guidelines/Quality/Q2 R1/Step4/Q2_R1_Guideline.pdf. Accessed 01/10, 2019.

[19] United States Pharmacopoeia (USP). 〈1174〉 Powder Flow. The United States Pharmacopoeia 37 - The National Formulary 32. 37th ed. Baltimore. United States; 2014. [20] United States Pharmacopoeia (USP). $\langle 616\rangle$ Bulk density and tapped density of powders. The United States Pharmacopoeia 37 - The National Formulary 32. 37th ed. Baltimore, United States; 2014.

[21] Blanver. Explosol. 2017; Available at: https://blanver.com.br/es/materiaprima/explosol/tipo/farmaceutica. Accessed 02/17, 2019.

[22] FMC ByoPolymer. AcDiSol. 2017; Available at: https://materialworld.com.tw/wpcontent/uploads/2017/09/FMC_AcDiSol_brochure_final2.pdf. Accessed 02/16, 2019.

[23] Rowe RC, Sheskey PJ, Cook WG, Fenton ME. Handbook of Pharmaceutical Excipients. Sixth Edition ed. UK: Pharmaceutical Press; 2009.

[24] Edward Aguilar-Diaz J, Garcia-Montoya E, Perez-Lozano P, Maria Sune-Negre J, Minarro M, Ramon Tico J. The use of the SeDeM Diagram expert system to determine the suitability of diluents-disintegrants for direct compression and their use in formulation of ODT. Eur. J. Pharm. Biopharm. 2009;73(3):414-423.

[25] Marais A, Song M, Villiers M. Effect of compression force, humidity and disintegrant concentration on the disintegration and dissolution of directly compressed furosemide tablets using croscarmellose sodium as disintegrant. TJPR 2003;2(1):125135.

[26] Eriksson L, Johansson E, Kattaneh-Wod N, Wikström C, Wold S. Design of Experiments: Principles and Applications. 1st ed. Sweden: Umetrics Academy; 2000.

[27] Ph. Eur. EP. 2.9.1. Disintegration of Tablets and Capsules. In: Council of Europe, editor. 8th ed. Strasbourg, France; 2014.

[28] Ph. Eur. EP. 2.9.7. Friability of Tablets. In: Council of Europe, editor. . 8th ed. Strasbourg, France; 2014.

[29] Ph. Eur. EP. 2.9.8. Tablet Breaking Force. In: Council of Europe, editor. . 8th ed. Strasbourg, France; 2014.

[30] United States Pharmacopoeia (USP). 〈1217〉 Tablet Breaking Force. The United States Pharmacopoeia 37 - The National Formulary 32. 37th ed. Baltimore, United States; 2014.

[31] Ph. Eur. EP. 2.9.40. Uniformity Of Dosage Units. In: Council of Europe, editor. . 8th ed. Strasbourg, France; 2014.

[32] Li XH, Zhao LJ, Ruan KP, Feng Y, Xu DS, Ruan KF. The application of factor analysis to evaluate deforming behaviours of directly compressed powders. Powder Technol 2003;247:47-54. 
[33] Patel S, Kaushal AM, Bansal AK. Compression physics in the formulation development of tablets. Crit Rev Ther Drug Carrier Syst 2006;23(1):1-65.

[34] Antikainen O, Yliruusi J. Determining the compression behaviour of pharmaceutical powders from the force-distance compression profile. Int J Pharm 2003;252(1-2):253261.

[35] Hersey JA, Reed JE. The effect of particle size on the consolidation of powders during compaction. Particle Size Analysis Conference 1970.

[36] Roberts RJ, Rowe RC. The Effect of Punch Velocity on the Compaction of a Variety of Materials. J Pharm Pharmacol 1985;37(6):377-384.

[37] ICH, The International Conference on Harmonisation. Stability Testing Of New

Drug Substances And Products Q1A(R2). 2003; Available at: http://www.ich.org/fileadmin/Public_Web_Site/ICH_Products/Guidelines/Quality/Q1A R2/Step4/Q1A R2 Guideline.pdf. Accessed 01/14, 2017.

[38] World Health Organization. Revision on Monograph on tablets. WHO 2011.

[39] Anusha B, Karike G, Maheshwari K, Sura RS. Formulation and in Vitro Evaluation of Oro Dispersible Tablets of Lorazepam. IAJPS 2018;5(5):3945-3953.

[40] Chen Y, Liang Z, Cen Y, Zhang H, Han M, Tian Y, et al. Development of oral dispersible tablets containing prednisolone nanoparticles for the management of pediatric asthma. Drug Des Devel Ther 2015;9:5815-25.

[41] Choudhary N, Avari J. Formulation and evaluation of taste mask pellets of granisetron hydrochloride as oro dispersible tablet. Braz. J. Pharm. 2015;51(3):569-578.

[42] Nanjwade V, Manvi F, Nanjwade K. Formulation and Evaluation of Dispersible Tablets of lomefloxacin HCL. Int J Drug Dev \& Res 2013;5(1):103-113.

[43] Setty CM, Prasad DVK, Gupta VRM, Sa B. Development of Fast Dispersible Aceclofenac Tablets: Effect of Functionality of Superdisintegrants. IJPS 2008;70(2):180185.

[44] Rutherford ME, Ruslami R, Maharani W, Yulita I, Lovell S, Van Crevel R, et al. Adherence to isoniazid preventive therapy in Indonesian children: A quantitative and qualitative investigation. BMC research notes 20122012 Jan 06;5:7-7.

[45] Biogrund. CompactCel TC. 2017; Available at:

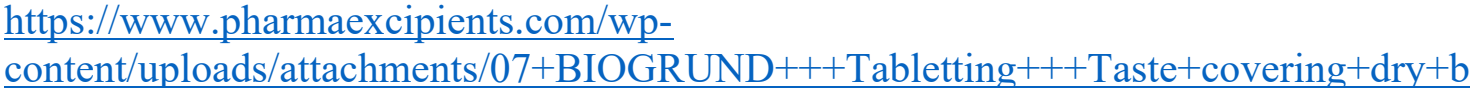
inder.pdf?t=1472197558. Accessed 02/15, 2019.

[46] United States Pharmacopoeia (USP). General Chapter $<1080>$. The United States Pharmacopoeia 37 - The National Formulary 32. 37th ed. Baltimore, United States; 2014. [47] Desai PM, Anbalagan P, Koh CJN, Heng PWS, Liew CV. Evaluation of tablet punch configuration on mitigating capping by a quality by design approach. Drug Deliv Transl Re. 2018;8(6):1635-1643.

[48] P. Anbalagan. A study on compaction punch design on tablet properties. Signapore: National University of Signapore; 2017.

[49] Heckel RW. Density-Pressure Relationships in Powder Compaction. Transactions of the Metallurgical Society of Aime 1961;221(4):671-675.

[50] Heckel RW. An Analysis of Powder Compaction Phenomena. Transactions of the Metallurgical Society of Aime 1961;221(5):1001-1008.

[51] Singh S, Mohan B. A pilot stability study on four-drug fixed-dose combination antituberculosis products. IJTLD 2003;7(3):298-303.

[52] Singh S, Bhutani H, Mariappan TT, Kaur H, Bajaj M, Pakhale SP. Behavior of uptake of moisture by drugs and excipients under accelerated conditions of temperature and humidity in the absence and the presence of light. 1. Pure anti-tuberculosis drugs and their combinations. Int J Pharm 2002;245(1-2):37-44. 

Tables:

\begin{tabular}{|c|c|c|c|}
\hline Factor & $\mathbf{- 1}$ & $\mathbf{0}$ & $\mathbf{+ 1}$ \\
\hline \% AcDiSol ${ }^{\circledR}(\mathbf{A}, \mathbf{w} / \mathbf{w})$ & 0.00 & 2.50 & 5.00 \\
\hline \% Explosol ${ }^{\circledR}(\mathbf{B}, \mathbf{w} / \mathbf{w})$ & 2.00 & 6.00 & 9.00 \\
\hline Compression Force, kN (C) & 11.0 & 14.0 & 16.0 \\
\hline
\end{tabular}

Table 1. Coded levels and values of design variables to the development of dispersible tablets.

\begin{tabular}{|c|c|c|c|c|c|c|c|c|c|}
\hline \multirow[b]{2}{*}{ Ingredient (mg) } & \multicolumn{9}{|c|}{ Formulation } \\
\hline & 1 & 2 & 3 & 4 & 5 & 6 & 7 & 8 & 9 \\
\hline Isoniazid (mg) & 50 & 50 & 50 & 50 & 50 & 50 & 50 & 50 & 50 \\
\hline Rifampicine (mg) & 75 & 75 & 75 & 75 & 75 & 75 & 75 & 75 & 75 \\
\hline AcDiSol ${ }^{\circledR}(\%)$ & - & - & - & 2.5 & 2.5 & 2.5 & 5 & 5 & 5 \\
\hline Avicel $(\%)$ & 57 & 53 & 50 & 54 & 50 & 47 & 52 & 48 & 45 \\
\hline Explosol® (\%) & 2 & 6 & 9 & 2 & 6 & 9 & 2 & 6 & 9 \\
\hline CompactCel $®(\%)$ & 7 & 7 & 7 & 7 & 7 & 7 & 7 & 7 & 7 \\
\hline CabOSil@ (\%) & 1 & 1 & 1 & 1 & 1 & 1 & 1 & 1 & 1 \\
\hline Luzenac $®(\%)$ & 2.5 & 2.5 & 2.5 & 2.5 & 2.5 & 2.5 & 2.5 & 2.5 & 2.5 \\
\hline Total (mg) & 900 & 900 & 900 & 900 & 900 & 900 & 900 & 900 & 900 \\
\hline
\end{tabular}

Table 2. Composition in $\mathrm{mg}$ and $\%(\mathrm{w} / \mathrm{w})$ of formulations 1 to 9 , each of which was compressed to the three compressions forces, to develop the dispersible tablets following the experimental design.

\begin{tabular}{|c|c|c|c|}
\hline API & INH & PZA & RFP \\
\hline Calibration curve & $\mathrm{A}=31925.3 \cdot \mathrm{C}$ & $\mathrm{A}=35181 \cdot \mathrm{C}$ & $\mathrm{A}=-150190+49378 \cdot \mathrm{C}$ \\
\hline $\mathbf{R}^{\mathbf{2}}$ & 0.99 & 0.99 & 0.98 \\
\hline CV (\%) & 3.11 & 3.32 & 0.89 \\
\hline Precision (\%, $\mathbf{1 \%} \%)$ & 0.28 & 0.16 & 97.7 \\
\hline Accuracy (\%, 97-103\%) & 98.0 & 97.7 & 3.10 \\
\hline Detection limit $(\boldsymbol{\mu g} / \mathbf{m l})$ & 1.70 & 1.74 & 9.40 \\
\hline Quantification limit $(\boldsymbol{\mu g} / \mathbf{m l})$ & 5.16 & 5.28 & \\
\hline
\end{tabular}

Table 3. Characteristic of the method used to the analysis by UHPLC of each API. A: Peak Area $(\mu \mathrm{V} \cdot \mathrm{sec})$.

$\mathrm{C}$ : Concentration $(\mu \mathrm{g} / \mathrm{ml})$. CV: coefficient of variation.

\begin{tabular}{|c|c|c|c|}
\hline \multicolumn{5}{|c|}{ Cpk } \\
\hline Time (min) & $\mathbf{5}$ & $\mathbf{1 0}$ & $\mathbf{1 5}$ \\
\hline INH & 0.89 & 0.61 & 3.79 \\
\hline PZA & 3.05 & 2.63 & 2.14 \\
\hline RFP & 3.18 & 1.98 & 2.53 \\
\hline
\end{tabular}

Table 4. Evolution of $\mathrm{CpK}$ over time for each API. 


\begin{tabular}{|c|c|c|c|c|c|}
\hline \multirow[b]{2}{*}{ Batch $\mathbf{N}^{o}$} & \multicolumn{3}{|c|}{ Factors } & \multicolumn{2}{|c|}{ Responses } \\
\hline & $A(\%, w / w)$ & B $(\%, w / w)$ & $\mathrm{C}(\mathrm{kN})$ & $\begin{array}{l}\text { Disintegration } \\
\text { time (seconds) }\end{array}$ & Friability (\%) \\
\hline 1 & 0.0 & 2.0 & 11 & 69 & 1.44 \\
\hline 2 & 0.0 & 2.0 & 14 & 145 & 0.95 \\
\hline 3 & 0.0 & 2.0 & 16 & 270 & 0.82 \\
\hline 4 & 0.0 & 6.0 & 11 & 80 & 1.36 \\
\hline 5 & 0.0 & 6.0 & 14 & 141 & 1.02 \\
\hline 6 & 0.0 & 6.0 & 16 & 195 & 0.83 \\
\hline 7 & 0.0 & 9.0 & 11 & 100 & 1.43 \\
\hline 8 & 0.0 & 9.0 & 14 & 132 & 0.97 \\
\hline 9 & 0.0 & 9.0 & 16 & 170 & 0.74 \\
\hline 10 & 2.5 & 2.0 & 11 & 124 & 1.09 \\
\hline 11 & 2.5 & 2.0 & 14 & 128 & 0.79 \\
\hline 12 & 2.5 & 2.0 & 16 & 140 & 0.75 \\
\hline 13 & 2.5 & 6.0 & 11 & 86 & 1.31 \\
\hline 14 & 2.5 & 6.0 & 14 & 120 & 0.91 \\
\hline 15 & 2.5 & 6.0 & 16 & 146 & 0.84 \\
\hline 16 & 2.5 & 9.0 & 11 & 85 & 1.79 \\
\hline 17 & 2.5 & 9.0 & 14 & 107 & 1.17 \\
\hline 18 & 2.5 & 9.0 & 16 & 130 & 0.90 \\
\hline 19 & 5.0 & 2.0 & 11 & 145 & 1.05 \\
\hline 20 & 5.0 & 2.0 & 14 & 155 & 0.78 \\
\hline 21 & 5.0 & 2.0 & 16 & 175 & 0.64 \\
\hline 22 & 5.0 & 6.0 & 11 & 124 & 1.53 \\
\hline 23 & 5.0 & 6.0 & 14 & 132 & 1.07 \\
\hline 24 & 5.0 & 6.0 & 16 & 141 & 0.88 \\
\hline 25 & 5.0 & 9.0 & 11 & 113 & 1.66 \\
\hline 26 & 5.0 & 9.0 & 14 & 121 & 1.10 \\
\hline 27 & 5.0 & 9.0 & 16 & 135 & 0.84 \\
\hline 28 & 2.5 & 6.0 & 14 & 128 & 1.02 \\
\hline 29 & 2.5 & 6.0 & 14 & 142 & 0.91 \\
\hline 30 & 2.5 & 6.0 & 14 & 139 & 0.93 \\
\hline
\end{tabular}

Table 5. Experimental Results: disintegration time and friability obtained with different batches of tablets according to the experimental design. A: AcDiSol ${ }^{\circledR}(\%, w / w)$. B: Explosol ${ }^{\circledR}(\%, w / w)$. C: Compression Force $(\mathrm{kN})$ 


\begin{tabular}{|c|c|c|}
\hline & Disintegration time (min) & Friability (\%) \\
\hline Model (P-value) & $<0.0001$ & $<0.0001$ \\
\hline R-Squared $\left(\mathbf{R}^{2}\right)$ & 0.81 & 0.94 \\
\hline Adjusted R-Squared ( $\left.\mathbf{R}_{\text {adj }}{ }\right)$ & 0.76 & 0.92 \\
\hline Predicted R-Squared $\left(\mathbf{Q}^{2}\right)$ & 0.57 & 0.88 \\
\hline Lack of Fit (P-value) & 0.19 & 0.36 \\
\hline
\end{tabular}

Table 6. Quality of the experimental design using regression analysis.

\begin{tabular}{|c|c|c|}
\hline \multicolumn{3}{|c|}{ Formulation 3 (Batch N 9) } \\
\hline Punches & 12-mm FFBE & 15-mm FFBP \\
\hline Compression Pressure (kN/cm2) & \multicolumn{2}{|c|}{9.00} \\
\hline Compression Force (kN) & 10.0 & 16.0 \\
\hline Tablet weight (mg) & 450 & 900 \\
\hline Disintegration time (seconds) & 150 & 170 \\
\hline Friability (\%) & 0.09 & 0.74 \\
\hline
\end{tabular}

Table 7. Comparation of tablet properties using the same compression pressure and composition but different punches.

\begin{tabular}{|c|c|c|c|c|c|c|c|c|}
\hline \multirow{2}{*}{\multicolumn{3}{|c|}{$\begin{array}{c}\text { Punches } \\
\text { Cycles/minute }\end{array}$}} & \multicolumn{3}{|c|}{ 15-mm FFBE } & \multicolumn{3}{|c|}{ 12-mm FFBP } \\
\hline & & & 10 & 25 & 50 & 10 & 25 & 50 \\
\hline \multirow{2}{*}{$\begin{array}{c}\text { Mass } \\
\text { variation }\end{array}$} & \multicolumn{2}{|c|}{ Average \pm SD } & $0.92 \pm 0.004$ & $0.90 \pm 0.004$ & $0.89 \pm 0.012$ & $0.45 \pm 0.002$ & $0.44 \pm 0.003$ & $0.41 \pm 0.002$ \\
\hline & \multicolumn{2}{|c|}{ RSD } & 0.43 & 0.44 & 1.32 & 0.53 & 0.57 & 0.53 \\
\hline \multicolumn{3}{|c|}{ Friability (\%) } & 0.85 & 0.87 & 1.01 & 0.09 & 0.14 & 0.17 \\
\hline \multicolumn{3}{|c|}{ Disintegration time (sec) } & 160 & 155 & 132 & 150 & 136 & 125 \\
\hline \multirow{2}{*}{$\begin{array}{c}\text { Tensile } \\
\text { Strength } \\
(\mathrm{N} / \mathrm{cm} 2) \\
\end{array}$} & \multicolumn{2}{|c|}{ Average \pm SD } & $171 \pm 9.82$ & $165 \pm 9.39$ & $159 \pm 3.64$ & $165 \pm 5.61$ & $151 \pm 4.10$ & $145 \pm 5.69$ \\
\hline & \multicolumn{2}{|c|}{ RSD } & 5.73 & 5.68 & 2.29 & 3.39 & 2.71 & 3.93 \\
\hline \multirow{6}{*}{$\begin{array}{c}\text { Content } \\
\text { Uniformity }\end{array}$} & \multirow{2}{*}{ INH } & DV, $\%$ & $102 \pm 2.64$ & $97.2 \pm 3.21$ & $101 \pm 3.06$ & $102 \pm 3.37$ & $99.1 \pm 4.41$ & $98.6 \pm 11.1$ \\
\hline & & AV & 6.74 & 9.05 & 7.35 & 8.10 & 10.59 & 11.09 \\
\hline & \multirow{2}{*}{ PZA } & DV, $\%$ & $100 \pm 0.87$ & $99.1 \pm 1.62$ & $97.7 \pm 1.45$ & $93.7 \pm 1.10$ & $92.9 \pm 1.02$ & $98.5 \pm 8.11$ \\
\hline & & AV & 2.08 & 3.88 & 4.27 & 7.46 & 7.99 & 8.12 \\
\hline & \multirow{2}{*}{ RFP } & DV, \% & $100 \pm 1.86$ & $99.5 \pm 2.35$ & $99.6 \pm 1.33$ & $92.75 \pm 1.17$ & $90.4 \pm 2.63$ & $98.5 \pm 10.6$ \\
\hline & & AV & 3.99 & 5.63 & 3.19 & 8.56 & 14.40 & 10.60 \\
\hline \multicolumn{3}{|c|}{ Fineness of dispersion } & $\mathrm{Ok}$ & $\mathrm{Ok}$ & $\mathrm{Ok}$ & $\mathrm{Ok}$ & $\mathrm{Ok}$ & $\mathrm{Ok}$ \\
\hline
\end{tabular}

Table 8. Variation of CQAs according to press speed for 12 and 15-mm punches. SD: standard deviation; RSD: relative standard deviation; DV: declared value; AV: acceptance value. 



\section{Figures:}

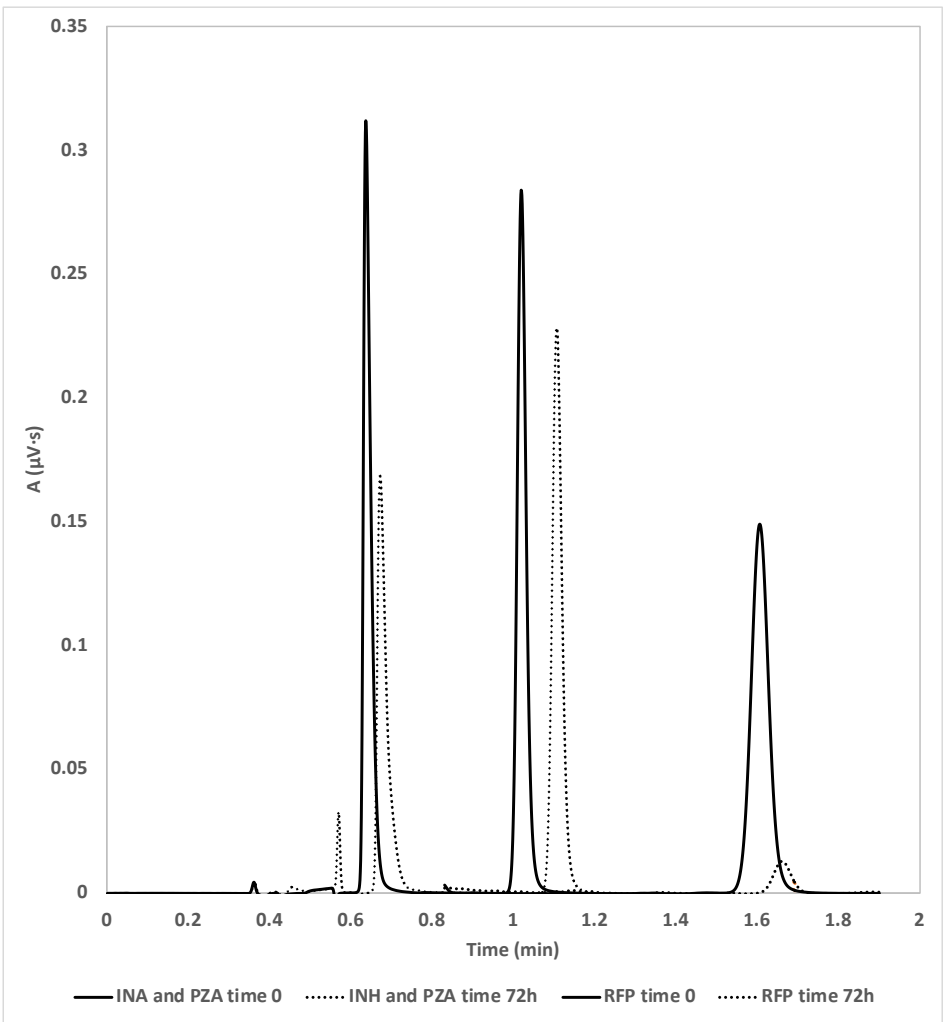

Figure 1. INH (0.6 min), PZA (1 min) and RFP (1.6 min) as pure patter chromatographic peaks (continuous bold line). Discontinuous line represents the decrease of signals for each API after $72 \mathrm{~h}$ of storage at $50^{\circ} \mathrm{C}$ in a medium with a $\mathrm{pH}$ of 7.

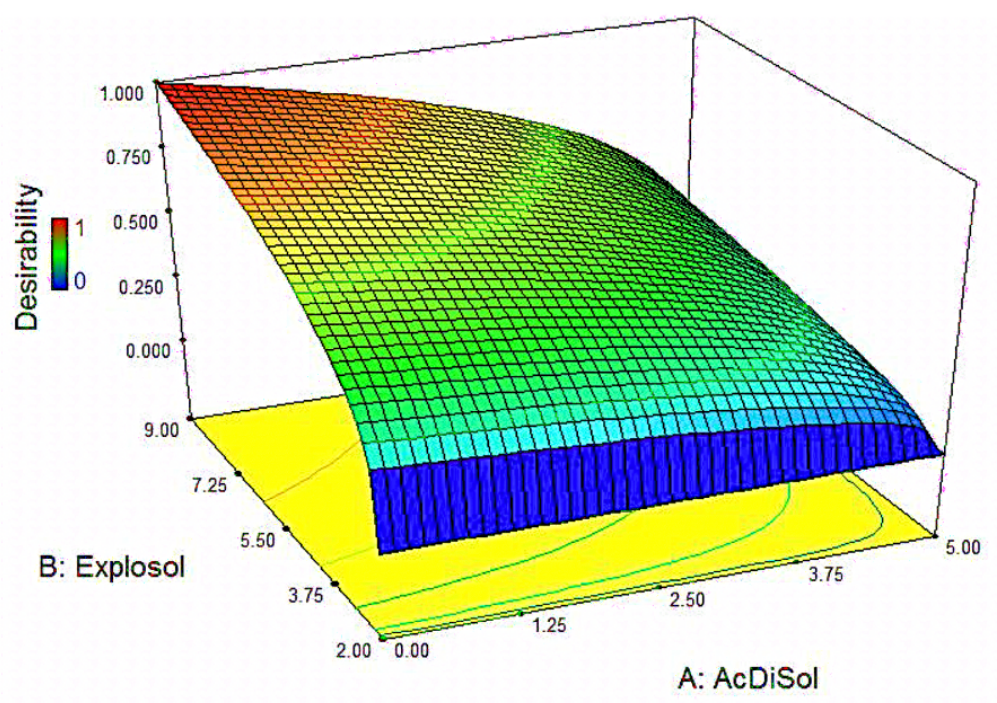

Figure 2. Response 3D-surface for factors $A$ and $B$ when $C$ is $16 \mathrm{kN}$. 


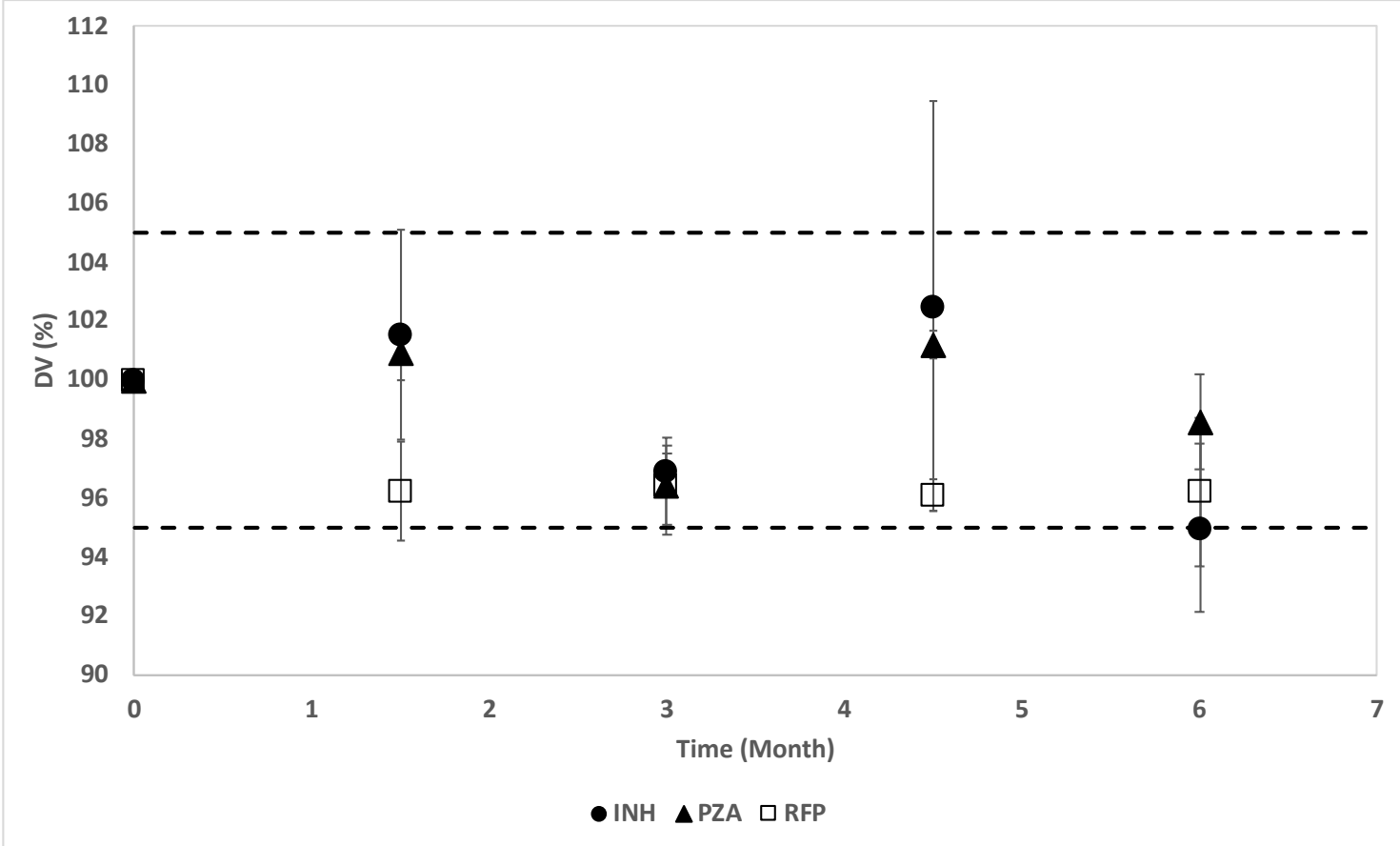

Figure 3. Stability of INH, PZA and RFP in $15 \mathrm{~mm}$ tablet under accelerated conditions. DV: Declared value. $n=3$. 